
zonafranca
EGMS:
IMG
CENTRO DE ESTUDIOS
INTERDISCIPLINARIOS SOBRE MUJERES
MAESTRIA "PODER Y SOCIEDAD
DESDE LA PROBLEMÁTICA DE GÉNERO"

\title{
"Ella es una obsesiva y él está aprendiendo": imaginarios y desigualdad material en las relaciones sexo-afectivas de miembros de la comunidad universitaria
}

\author{
María de las Nieves Puglia \\ Candela Giménez Bach ** \\ María Hereñú *** \\ Candela Gancedo García ****
}

\section{Resumen}

Los vínculos sexo-afectivos en el ámbito universitario han sido estudiados fundamentalmente desde la perspectiva de las violencias de género. Existe escasa evidencia sobre las desigualdades de género sobre las cuales estas relaciones se apoyan. Este artículo busca interrogar la dimensión económicamaterial de los vínculos sexo-afectivos. En este sentido, se propone analizar las

* Centro de Estudios Sociales de la Economía, Instituto de Altos Estudios Sociales/Universidad Nacional de San Martín. Contacto: mariapuglia@gmail.com

** Instituto de Altos Estudios Sociales/Universidad Nacional de San Martín. Contacto: bachcandela94@gmail.com

*** Facultad de Ciencias Sociales/Universidad de Buenos Aires. Contacto: mariaherenu18@gmail.com

**** Facultad de Ciencias Sociales/Universidad de Buenos Aires. Contacto: cande.gancedo@hotmail.com

Puglia, María de las Nieves; Giménez Bach, Candela; Hereñú, María; Gancedo García, Candela. "Ella es una obsesiva y él está aprendiendo': imaginarios y desigualdad material en las relaciones sexo-afectivas de miembros de la comunidad universitaria" en Zona Franca. Revista del Centro de estudios Interdisciplinario sobre las Mujeres, y de la Maestría poder y sociedad desde la problemática de Género, N²8, 2020 pp. 204-236. ISSN, 2545-6504 Recibido: 4 de julio 2020; Aceptado: 6 de noviembre 2020

Revista Zona Franca- Centro de estudios interdisciplinario sobre las mujeres (CEIM)- Maestría poder y sociedad desde la problemática de género (MG), Rosario, Argentina. ISSN, 2545-6504 http://zonafranca.unr.edu.ar/index.php/ZonaFrancal Número 28 (2020). 
figuras bajo las cuales emergen los imaginarios en torno a la gestión del dinero y de los cuidados en las relaciones sexo-afectivas de quienes participan del espacio universitario (docentes, no docentes y estudiantes).

Para responder esta pregunta se recurrió a una metodología cualitativa, a través de la técnica de entrevistas en profundidad. A partir de este abordaje, se identificaron dos grandes dimensiones de análisis. En primer lugar, las escenas que muestran las figuras y metáforas que usan las personas entrevistadas acerca de la gestión del dinero en el vínculo sexo-afectivo y las ficciones que recrean en relación con la igualdad. En segundo lugar, ahondaremos en la distribución efectiva de los cuidados del hogar y de las personas (en especial, hijos/as menores) que sucede en esas relaciones.

Palabras clave: Desigualdades de género- gestión del dinero cuidados- universidad-vínculos sexo-afectivos

\section{"She is obsessive and he is learning": imaginaries and material inequality in the sex-affective relationships of members of the university community}

\section{Abstract}

Sex-affective relations in the university environment have been studied fundamentally from the perspective of gender violence. There is little evidence of the gender inequalities on which these relationships support. This article seeks to interrogate the economic-material dimension of sex-affective ties. In this sense, it is proposed to analyze the figures under which the imaginary around the management of money and care in the sex-affective relationships of those who participate in the university space (teachers, non-teachers and students) emerge.

To answer this question, a qualitative methodology was applied through the in-depth interview technique. From this approach, two large dimensions of analysis were identified. In the first place, the scenes that show the figures and metaphors that the interviewees use about the management of money in the sex-affective bond and the fictions that they recreate in relation to equality. Secondly, we will delve into the effective distribution of home and person care (especially minor children) that occurs in these relationships.

Key words: gender inequalities- money management- careuniversity- sexafective relations

\section{Introducción}

Revista Zona Franca- Centro de estudios interdisciplinario sobre las mujeres (CEIM)- Maestría poder y sociedad desde la problemática de género (MG), Rosario, Argentina. ISSN, 2545-6504 http://zonafranca.unr.edu.ar/index.php/ZonaFrancal Número 28 (2020). 
En el contexto de un movimiento feminista revitalizado que pareciera cuestionarlo todo, la demanda del estudiantado' así como los espacios de políticas de género que crecieron en las distintas universidades del país prepararon el terreno para el cuestionamiento a las desigualdades y violencias de género y, por ende, buscar construir relaciones más justas. En el marco de las entrevistas realizadas a los tres claustros (docente, no docente y estudiantil) de la Universidad Nacional de San Martín (UNSAM), nos asombró el enorme esfuerzo con el que los sujetos universitarios tratan de coincidir con esos cuestionamientos. Sean estudiantes, docentes o no docentes, recurren a describir, con una frecuencia extraordinaria, sus relaciones sexo-afectivas como equitativas. Pero a lo largo de las conversaciones, ese imaginario se distanciaba de la heterogeneidad de situaciones que muestran desigualdades materiales profundas, en especial, en lo que hace a la distribución del trabajo de los cuidados del hogar y de personas a cargo.

En este sentido nos preguntamos sobre los modos en que el imaginario de las relaciones sexo-afectivas equitativas que sostienen los miembros de la comunidad universitaria (docentes, no docentes y estudiantes) se tensiona con la reproducción de desigualdades materiales. Está en el espíritu de esta pregunta interrogar una dimensión muy poco estudiada en los trabajos sobre desigualdades y violencias de género, que es la dimensión económica-material de los vínculos sexo-afectivos.

Para responder nuestra pregunta analizaremos dos grandes dimensiones. En primer lugar, las escenas que muestran las figuras y metáforas que usan las personas entrevistadas acerca de la gestión del dinero en el vínculo sexo-afectivo y las ficciones que recrean en relación con la igualdad. En segundo lugar,

\footnotetext{
' A lo largo de este artículo seguimos las recomendaciones de la Organización de Naciones Unidas para adoptar un lenguaje inclusivo en cuanto al género. Las recomendaciones pueden consultarse aquí https://www.un.org/es/gender-inclusive-language/guidelines.shtml
}

Revista Zona Franca- Centro de estudios interdisciplinario sobre las mujeres (CEIM)- Maestría poder y sociedad desde la problemática de género (MG), Rosario, Argentina. ISSN, 2545-6504 http://zonafranca.unr.edu.ar/index.php/ZonaFranca| Número 28 (2020). 
ahondaremos en la distribución efectiva de los cuidados del hogar y de las personas (en especial, hijos/as menores) que sucede en esas relaciones.

En un principio pensábamos que el artículo versaría sobre violencia de género de tipo económica o patrimonial. En verdad, en las entrevistas no se reflejaban situaciones de control o restricción respecto de los ingresos y/o patrimonio de las mujeres por parte de los hombres, a diferencia de lo que han encontrado otras investigadoras sobre las mujeres de clases bajas que proveían un salario de su trabajo remunerado extradoméstico, como mostró el conocido estudio de Lourdes Benería y Martha Roldán (1987) en México. En cambio, nos encontramos con un hallazgo: la comunidad universitaria estaba casi en su totalidad preocupada por sostener discursivamente la idea de que sus relaciones sexo-afectivas -con distintos grados de formalidad- eran igualitarias. De ningún modo pensamos que se trata de una comunidad homogénea, pero quisimos extraer esta particular retórica que transversaliza las experiencias de los tres claustros. Es por esto que trabajamos sobre las figuras en las que se sostiene esta ficción. Optamos por denominarlas de este modo porque conviven con desigualdades en las valoraciones de la gestión del dinero respecto a las mujeres y a los hombres, y porque además se van a montar sobre desigualdades en el plano de la distribución de las tareas del cuidado. Es este imaginario sobre el cual tuvimos que trabajar para comprender el modo en que se tendía un velo sobre las desigualdades materiales en estos vínculos.

La relación entre afectos y dinero ha comenzado a estudiarse en las últimas décadas. Sin embargo, sigue siendo materia de controversia el modo en que se articulan y su compatibilidad. Lo cierto es que las parejas hacen importantes esfuerzos por compatibilizar los dos planos. Pero el plano material también se compone de las tareas cotidianas que aseguran la vida de las personas que participan de un vínculo o una familia. Es en este plano que se producen formas singulares de la extracción de valor sobre la capacidad de amar en las que han sido socializadas mayormente las mujeres.

Revista Zona Franca- Centro de estudios interdisciplinario sobre las mujeres (CEIM)- Maestría poder y sociedad desde la problemática de género (MG), Rosario, Argentina. ISSN, 2545-6504 http://zonafranca.unr.edu.ar/index.php/ZonaFranca| Número 28 (2020). 
Este artículo se enmarca en un proyecto más amplio de investigación, denominado "Representaciones sociales y experiencias en torno a la violencia de género y sexualidades en estudiantes, docentes y no docentes en la Universidad Nacional de San Martín", que se desarrolló entre 2017 y 2019. Se trató de una investigación de diseño cualitativo. La técnica de recolección de información utilizada fue la entrevista semi-estructurada, que nos permitió delimitar el contenido de las preguntas y a su vez conservar el enfoque en profundidad. La realización de entrevistas tuvo como objetivo permitir a las personas entrevistadas utilizar su propio lenguaje y habilitar emergentes que no hayamos tenido en cuenta en instancias previas de la investigación.

Todas las personas entrevistadas formaban parte de la población de la Universidad Nacional de San Martín y pertenecían a alguno de los tres claustros: docente, no docente o estudiantes. La muestra no fue aleatoria, sino que se buscó activamente casos de todos los claustros, géneros, edades y unidades académicas. Se realizaron 62 entrevistas, 20 a estudiantes y 42 a docentes y no docentes. Por otro lado, es de los claustros docente y no docente de donde extraemos la mayor cantidad de relatos incluidos en este trabajo y en estos casos las personas se encuentran mayoritariamente entre los 30 y 40 años. Esto nos hace pensar que se puede tratar de sujetos menos permeables a sostener prácticas igualitarias en la intimidad de sus vínculos más allá del discurso, a diferencia de quienes se encuentran en el claustro estudiantil y cuyas edades oscilan, generalmente, los 20 años.

La entrevista tuvo como objetivo indagar en los distintos claustros sobre sus espacios de encuentros, salidas, la gente con quien se relacionan, tanto fuera como dentro de la universidad, ya sean amigos, familia, pareja, y cómo se sienten en la Universidad. El análisis que pretende este artículo se circunscribe fundamentalmente a las respuestas de las personas a las siguientes preguntas: En relación con el cuidado del hogar, ¿quién se encarga de las tareas? ¿Cómo se distribuyen los gastos en tu casa? ¿Quién paga qué? ¿En qué se basan las

Revista Zona Franca- Centro de estudios interdisciplinario sobre las mujeres (CEIM)- Maestría poder y sociedad desde la problemática de género (MG), Rosario, Argentina. ISSN, 2545-6504 http://zonafranca.unr.edu.ar/index.php/ZonaFranca| Número 28 (2020). 
decisiones? ¿Las personas que viven en tu vivienda de dónde obtienen los ingresos cada uno/a? ¿Trabajan o tienen otra fuente de ingreso? ¿Cuántas horas? ¿Cuánto gana cada uno/a de los/as miembros que viven en tu vivienda, incluido/a vos?

Resulta importante aclarar que para la realización de este texto se tomó la decisión metodológica de focalizar el análisis en las personas cis que formasen vínculos heterosexuales. Esto se debió a dos razones. En primer lugar porque más del $70 \%$ de quienes relataron situaciones con sus parejas lo hicieron en referencia a vínculos sexo-afectivos heterosexuales, decidimos ceñirnos a analizar esas dinámicas. En segundo lugar, porque otras personas del equipo de investigación dedicarán un análisis detallado de las trayectorias de personas no binarias y de los vínculos gays y lésbicos.

Por último, queremos señalar que si bien no se construyeron clasificaciones respecto de las clases sociales a las cuales pertenecen las personas entrevistadas, la universidad se caracteriza por tener estudiantes que pertenecen, principalmente, a la Ciudad de Buenos Aires y, en segundo lugar, al partido de San Martín, las zonas norte y oeste del conurbano bonaerense. El último informe de gestión de la UNSAM" publicado que corresponde al año 2018 indica que el $75 \%$ del estudiantado ingresante es primera generación universitaria y que el $65 \%$ trabaja o busca trabajo. El claustro docente posee en su interior tanto trayectorias de traslado desde instituciones más longevas y tradicionales, como algunos institutos de investigación históricos o la Universidad de Buenos Aires, así como docentes jóvenes que hicieron toda su carrera en la UNSAM, con la particularidad de que algunas de esas personas fueron estudiantes de grado y posgrado de la misma institución. Algo similar ocurre con el claustro no docente, ya que las pertenencias de las personas que forman parte del espacio de esta universidad son múltiples. Una misma persona puede pertenecer o haber pertenecido en algún

" Informe de gestión 2018. Universidad Nacional de San Martín. Puede consultarse en http://www.unsam.edu.ar/institucional/informe-de-gestion-2018.pdf

Revista Zona Franca- Centro de estudios interdisciplinario sobre las mujeres (CEIM)- Maestría poder y sociedad desde la problemática de género (MG), Rosario, Argentina. ISSN, 2545-6504 http://zonafranca.unr.edu.ar/index.php/ZonaFranca| Número 28 (2020). 
momento de su carrera, a los tres claustros. Dadas estas características, no podemos afirmar que exista una pertenencia homogénea a determinada clase social. Sin embargo, cuando Bourdieu y Passeron (2009) estudiaron la universidad francesa notaron que la procedencia era activamente dejada de lado en el mantenimiento de la illusio sobre el juego académico. Por esta razón existen sentidos que se construyen colectivamente en la comunidad universitaria y que pueden compartirse en mayor o menor grado. Aquí interpretamos que ese imaginario sobre la igualdad que se repite con tanta frecuencia en las entrevistas, se debe a que las personas que participan del espacio universitario, también colaboran en formar parte de un juego en el que sostener la idea de la igualdad forma parte de la acumulación de capital cultural, un recurso largamente asociado a las clases medias en Argentina (Svampa, 2005).

La UNSAM tiene dos particularidades que se destacan en lo pertinente a este artículo y que atañe a las trayectorias de las personas que habitan el campo. En primer lugar, existen casos en que las personas entrevistadas eran estudiantes y no docentes a la vez. Estos casos son muy comunes en la universidad, muchas personas que cursan carreras también trabajan en tareas administrativas y de gestión. En sus 25 años de existencia, la universidad es un espacio joven y, muchas de las personas que se forman y trabajan allí tienen múltiples roles. Esta afirmación no es generalizable y no queremos decir con esto que exista una sola forma de habitar la universidad, pero sí es frecuente encontrarse con, por ejemplo, no docentes que son estudiantes y estudiantes de posgrado que son docentes de las carreras de pregrado y grado. Esta característica de entrelazamiento de las trayectorias de estudio y laborales construyen sujetos que no siempre son distinguibles por su pertenencia a un claustro, de modo tal que una persona que estudia allí no siempre se distingue radicalmente de un docente. Es importante señalar que las entrevistas con estudiantes nos permitieron conocer, no solo el modo en que construyen sus propios vínculos de pareja, sino también el modo en

Revista Zona Franca- Centro de estudios interdisciplinario sobre las mujeres (CEIM)- Maestría poder y sociedad desde la problemática de género (MG), Rosario, Argentina. ISSN, 2545-6504 http://zonafranca.unr.edu.ar/index.php/ZonaFranca| Número 28 (2020). 
que reponen la relación entre sus padres. Así pudimos identificar algunas características del factor generacional de los patrones en los vínculos.

La segunda característica notoria es que la universidad lleva más de 5 años consolidando sus políticas de género. Esto la hizo pionera, junto a un puñado de otras instituciones, en la elaboración de protocolos de actuación frente a los casos de violencia de género y de discriminación por orientación sexual. Además del instrumento del protocolo, la institución posee una oferta de formación, talleres, capacitaciones con perspectiva de género y ha trabajado en torno a las violencias con mucha fuerza. Una de las pruebas de esto es la Consejería Integral que tiene un área especializada en la atención de personas afectadas, y que desde 2018 forma parte de lo que pasó a llamarse la Dirección de Género y Diversidad Sexual. Este espacio es uno de los más robustos y uno de los que más trabajo tiene dentro del sistema universitario nacional. Estamos convencidas de que el hecho de que la universidad hizo de las políticas de género una de sus prioridades, produjo ciertas disposiciones en los discursos relevados en este artículo. La presencia de la Dirección en la vida cotidiana de docentes, no docentes y estudiantes es significativa, ya sea por las intervenciones de la Consejería en las distintas unidades académicas, como por las actividades y capacitaciones impulsadas desde la Dirección. Probablemente, esta presencia haya impregnado las sensibilidades y los discursos en torno a las desigualdades y las violencias de género.

Los límites porosos entre claustros y la presencia de un espacio de género robusto son dos variables fundamentales por las cuales decidimos identificar las figuras en común, mostrando esa illusio, ese juego compartido, en lugar de reparar en otros matices o diferencias al interior de la comunidad.

Respecto del análisis, el total de entrevistas se volcaron en una matriz que identificaba las dimensiones analíticas. Esa primera grilla, con la información de todas las entrevistas del proyecto, nos permitió comprender el contexto y el hilo de

Revista Zona Franca- Centro de estudios interdisciplinario sobre las mujeres (CEIM)- Maestría poder y sociedad desde la problemática de género (MG), Rosario, Argentina. ISSN, 2545-6504 http://zonafranca.unr.edu.ar/index.php/ZonaFranca| Número 28 (2020). 
conversación de cada diálogo. De allí se realizó una primera codificación para extraer los testimonios completos donde identificamos las experiencias en torno a la gestión del dinero y la distribución de las tareas de cuidado en los vínculos. Por último, realizamos una segunda codificación sobre los extractos anteriores, para obtener las figuras que se repetían en los tres claustros y que diferenciaban las categorías específicamente abocadas a explicar esas dos dimensiones que son objeto de este artículo.

\section{Marco teórico y antecedentes}

Una de las primeras reflexiones sobre el vínculo entre relaciones sexoafectivas y dinero fue de Viviana Zelizer (2006). Su análisis de las relaciones matrimoniales, así como de las strippers, por dar dos ejemplos, mostró de modo magistral cómo las personas realizan importantes esfuerzos por articular sexo y dinero (Zelizer, 2006). Así como las mujeres casadas pueden utilizar sus ingresos en dinero para sentirse habilitadas para negarse a sostener relaciones sexuales con sus maridos, una mujer que trabaja de stripper aleja todo rastro de monetización de sus relaciones íntimas. Una lo utiliza para negociar la frecuencia del sexo y la otra para separar los servicios pagos de sus relaciones íntimas.

Su trabajo dejó una matriz de análisis para analizar casos empíricos concretos a través de su perspectiva sobre las "esferas hostiles". Esto es, cuando se pueden identificar dos esferas de la vida que se dividen y que, cuando se cruzan, una contamina a la otra. Según esta perspectiva, la intimidad y el dinero no deberían mezclarse pues el segundo corrompería al primero (Zelizer, 2009). No obstante las personas constantemente están negociando dineros y afectos. La gestión cotidiana del presupuesto de un hogar, las mensualidades que los padres le dan a sus hijos, las compras conjuntas, los regalos en dinero entre amigos, son prueba de ello.

Revista Zona Franca- Centro de estudios interdisciplinario sobre las mujeres (CEIM)- Maestría poder y sociedad desde la problemática de género (MG), Rosario, Argentina. ISSN, 2545-6504 http://zonafranca.unr.edu.ar/index.php/ZonaFrancal Número 28 (2020). 
A pesar de las preocupaciones por la hostilidad, Arlie Hochschild (2011) lleva algunas décadas demostrando que la intimidad y el mercado tienen un vínculo estrecho. En su análisis de parejas heterosexuales casadas y homosexuales comprometidas, analiza lo que ella denomina "economía de la gratitud". Su planteo es interesante porque muestra que según se dirima la balanza entre dones (lo que los miembros de la pareja aportan a la misma) y gratitudes (la sensación de estar en deuda con la otra persona) en la gestión cotidiana de los ingresos de cada miembro y las tareas domésticas y de cuidado es que se irán configurando las relaciones de poder entre los miembros (Hochschild, 2011). "Cuando el poder económico de la mujer aumenta, el grado en que el esposo lo percibe como un don y no como una amenaza o una carga determina cuánto poder adicional gana con sus nuevos recursos" (Canevaro, 2008: 207).

Con cierta relación, Anna Jónasdóttir (1993; 2011) propuso que aún en sociedades formalmente igualitarias como las nórdicas, existe explotación de los hombres sobre las mujeres. Este concepto va un poco más profundo que el de violencia, pues permite comprender las dinámicas vinculares en relación a dinámicas de extracción de valor. El amor humano, visto desde una perspectiva marxista, es una actividad creadora de vida y que en las relaciones socio-sexuales heterosexuales donde ambos miembros tienen trabajos remunerados, existe explotación de la capacidad de amar de las mujeres, aún bajo consentimiento. Si bien su análisis está contextualizado en otras latitudes y se trata de un aporte teórico, podemos decir que desde el estudio empírico que sustenta este texto, entre las personas que entrevistamos para este trabajo también existe una sensación compartida de que varones y mujeres están en posiciones equitativas. Esto adquiere aún más relevancia si tenemos en cuenta las estructuras económicas y relaciones de género que en la modernidad configuran un yo romántico en las relaciones heterosexuales, donde confluyen la lógica emocional y la lógica económica, como ha demostrado Eva Illouz (2012).

Revista Zona Franca- Centro de estudios interdisciplinario sobre las mujeres (CEIM)- Maestría poder y sociedad desde la problemática de género (MG), Rosario, Argentina. ISSN, 2545-6504 http://zonafranca.unr.edu.ar/index.php/ZonaFranca| Número 28 (2020). 
Cuando hablamos de una perspectiva materialista sobre el amor, Silvia Federici resulta ineludible. Para la autora (2018) el trabajo de cuidados no remunerado y habitualmente sostenido por las mujeres es uno de los pilares de la dominación masculina y de la producción capitalista. El amor como trabajo no pago constituye uno de los pilares sobre los que se erige lo que históricamente se construyó como trabajo productivo remunerado asociado al mundo de los hombres. El trabajo de Federici (2018) es importante porque nos permite conectar las dinámicas vinculares con las formas de acumulación del capital, de modo tal que no podamos entender estas relaciones como escindibles de las lógicas de acumulación.

Más recientemente, algunos estudios han tomado la herencia de Zelizer para contribuir a pensar una sociología del dinero. Ariel Wilkis (2013) tradujo esto en distintos tipos de dinero a través de su estudio en los sectores populares en el conurbano bonaerense. Existirían dineros militados, dineros donados, dineros sacrificados, dineros ganados, dineros cuidados, dineros prestados. Intenta mostrar que el dinero vehiculiza "valores morales en lógicas monetarias plurales (mercantiles y no mercantiles, formales e informales, familiares y barriales, políticas y religiosas, legales e ilegales)" (Wilkis, 2013: 28). En conexión con estas ideas, María de las Nieves Puglia trabajó en torno a los sentidos del dinero en las relaciones sexuales pagas, en especial en la capacidad de diferenciar clientes y vínculos íntimos (2016), así como en la sensación de autonomía que produce el dinero propio cuando las mujeres ingresan al mercado del sexo (2017). En relación a los vínculos amorosos, Marta Ibáñez Pascual (2008) ha analizado el funcionamiento de la "bolsa común" o dinero compartido por parejas españolas como el ideal de gestión del dinero. Ella muestra que la posición material estructura el ideal de género y viceversa, de modo que el modelo de gestión del dinero funciona como estructurante y como estructurado. En esta línea, Amaia Agirre Miguélez (2015) muestra que existe una tensión entre la negociación del dinero y el ideal de igualdad que sostienen las parejas homosexuales y

Revista Zona Franca- Centro de estudios interdisciplinario sobre las mujeres (CEIM)- Maestría poder y sociedad desde la problemática de género (MG), Rosario, Argentina. ISSN, 2545-6504 http://zonafranca.unr.edu.ar/index.php/ZonaFranca| Número 28 (2020). 
heterosexuales en el País Vasco. Si bien las negociaciones explícitas las acercan a la paridad, porque permiten distinguir entre dinero propio y dinero común, el ideal del amor romántico incompatibiliza amorosidad con la discusión sobre los recursos económicos. Es así que los distintos modelos de propiedad del dinero tienen consecuencias sobre las relaciones de poder entre parejas. Marentes (2020) recientemente ha estudiado cómo parejas gais de la Ciudad de Buenos Aires imprimen sentidos al dinero como expresión del estado del vínculo.

Respecto de los vínculos sexo-afectivos en el espacio universitario, el trabajo de Rafael Blanco (2014) fue pionero, reconociendo la universidad como espacio sexuado. Esta investigación abrió un campo que se alimentó de los aportes que investigadoras que se dedicaron tanto al estudio como a la intervención sobre situaciones de violencia de género en las universidades nacionales. Es así que sus estudios se centraron en las violencias de género entre e intra claustros a partir de sus experiencias en los espacios de género institucionalizados. En Rosario, Florencia Rovetto y Noelia Figueroa (2017) y en Buenos Aires, y específicamente en la UNSAM, Vanesa Vázquez Laba y Mariana Palumbo (2019) sostienen una línea de trabajo de largo alcance sobre las violencias suscitadas entre estudiantes, con el antecedente del estudio llevado adelante por esta última autora (2018). Estos trabajos fundamentales para entender las relaciones afectivas en la universidad se han centrado en la violencia simbólica que es la que predomina a través de los comentarios y chistes sexistas que suelen circular por aulas y pasillos. Este trabajo hace un aporte a la dimensión material de esos vínculos que no solo fueron poco estudiadas, sino que, en muchos casos, pueden contribuir a entender las desigualdades sobre las cuales emergen las violencias simbólicas tan singulares del espacio universitario que estos estudios han relevado.

\section{La gestión del dinero en la pareja: entre la igualdad imaginada y} los estereotipos

Revista Zona Franca- Centro de estudios interdisciplinario sobre las mujeres (CEIM)- Maestría poder y sociedad desde la problemática de género (MG), Rosario, Argentina. ISSN, 2545-6504 http://zonafranca.unr.edu.ar/index.php/ZonaFranca| Número 28 (2020). 
En un análisis transversal de las entrevistas, observamos que los acuerdos sobre el dinero suelen ser (o aparentan ser) más igualitarios que los acuerdos sobre las tareas de cuidado y del hogar. A partir de la lectura de todas las entrevistas, identificamos dos pares de figuras que les permitieron a los sujetos expresarse. En cuanto a los acuerdos monetarios dentro de la pareja, distinguimos dos acuerdos típicos que, si bien suenan similares, responden a distintos ideales de pareja. La bolsa común hace referencia al acuerdo por medio del cual la pareja comparte el total de sus ingresos y el 50/50 es el acuerdo por el cual se dividen equitativamente los gastos, pero que permite mantener cierta independencia de en los ingresos de los participantes del vínculo. Por otro lado, identificamos dos figuras que también aparecen recurrentemente en las respuestas de las personas entrevistadas cuando se indaga sobre quién administra el dinero: la imagen de "la mujer gestora", que refiere a la idea de que las mujeres son más hábiles para la administración del dinero y las responsabilidades del hogar; y "el hombre incapaz", su figura contraria.

Las personas realizan grandes esfuerzos por compatibilizar la vida íntima con la gestión del dinero que utilizan cotidianamente. En este sentido, diseñan dispositivos, más o menos sofisticados, que se corresponden con la concepción de pareja. Viviana Zelizer (2009) fue pionera en descubrir que las relaciones que implican intimidad estaban sometidas a constantes negociaciones que lograran compatibilizar las formas de circulación del dinero. El dinero en la pareja está muy poco explorado, pero es una de las dimensiones que sostiene la intimidad, pues administrado de cierto modo expresa las formas que concibe el vínculo. Lo que media entre la lógica económica y la lógica de la intimidad son los acuerdos (explícitos o implícitos) entre las partes y los modelos o imaginarios que las personas se esfuerzan por sostener para transitar las relaciones sexo-afectivas.

En las entrevistas, la mayor parte de las personas que sostienen una pareja heterosexual, más o menos formal, buscan un modelo de "equilibrio" o de "mitad y

Revista Zona Franca- Centro de estudios interdisciplinario sobre las mujeres (CEIM)- Maestría poder y sociedad desde la problemática de género (MG), Rosario, Argentina. ISSN, 2545-6504 http://zonafranca.unr.edu.ar/index.php/ZonaFrancal Número 28 (2020). 
mitad" entre los miembros de la pareja en lo que hace a la distribución de gastos del hogar compartido.

\subsection{La bolsa común romántica y la división equitativa}

El cálculo en los vínculos es un rasgo moderno que ha sido extensamente trabajado por Eva Illouz (2012). La autora aborda la conjunción entre lo emocional y lo económico mostrando cómo la racionalidad, el interés y la competencia forman parte de la dinámica del mercado amoroso heterosexual. En este sentido, la amorosidad moderna contempla ciertas reglas que implican el cálculo en los vínculos.

Como mencionamos anteriormente, una de las figuras que aparece reiteradas veces en las respuestas de las personas acerca de cuáles son los acuerdos en torno al dinero al interior de la pareja, es la de bolsa común. Siguiendo lo planteado por Ibáñez Pascual (2008), este concepto hace referencia a la unión de los ingresos de ambas partes, decisión que aparece como natural. Algunas personas consignaban la existencia literal de una lata 0 un espacio destinado para tal fin. Tal es así que los miembros de la pareja separan dinero de sus ingresos o retiran de sus cuentas bancarias para colocar una parte en ese fondo. Luego, de allí se extrae lo que será utilizado para las compras de la comida, el pago de servicios y de impuestos, principalmente.

Este fondo común es concebido como un símbolo de confianza, ya que implica que ambas partes percibirán el dinero como un bien colectivo y no como individual. En este sentido, el acuerdo de compartir la totalidad del ingreso, funciona como uno de los pilares que sostiene el vínculo sexo-afectivo y permite llevar adelante proyectos de vida en común. Tal es el caso de una mujer nodocente de 35 años que nos comentó que percibir el dinero con su pareja conjuntamente hace que sienta real la relación: "(...) Como que la plata lo hace concreto a ese proyecto de vida que yo tengo con él. Entonces me hace sentir

Revista Zona Franca- Centro de estudios interdisciplinario sobre las mujeres (CEIM)- Maestría poder y sociedad desde la problemática de género (MG), Rosario, Argentina. ISSN, 2545-6504 http://zonafranca.unr.edu.ar/index.php/ZonaFranca| Número 28 (2020). 
segura, no sé (...)". A su vez, en estos relatos aparece reiteradamente el desinterés en el dinero, visto como algo pasajero. Así lo expresó una docente de 43 años: "Tenemos cada uno su cuenta por una cuestión de que te depositan el sueldo, pero, no hay ninguna división. La plata va y viene (...) es como un fondo común." A pesar de que la entrevistada da cuenta de que con su pareja perciben sus ingresos en cuentas bancarias diferenciadas, el acuerdo responde a la figura de bolsa común ya que ponen en común la totalidad de sus ingresos.

En este tipo de vínculos el dinero está naturalmente al servicio de la pareja/familia, entendiendo que el interés familiar está por encima del interés individual. Siguiendo a la autora Agirre Miguelez (2015), esto puede explicarse por la presencia del ideal del amor romántico imperante en nuestra sociedad, el cual no permite la coexistencia entre los lazos afectivos y la defensa de intereses individuales. El ideal del amor romántico percibe como negativo el dinero individual ya que la formación de una pareja debe significar la entrega total de las partes. En especial, esta idea aparece asociada a la familia cuando existen hijos y/o hijas. Un docente comentó que: "No existe el concepto "mi plata" y "tu plata", eh, o sea, cuando estás en una familia (...) es lo mismo...".

La otra figura recurrente es la del 50/50. Hace referencia a las parejas que mantienen un acuerdo económico en el cual, si bien los gastos se dividen igualitariamente, cada persona mantiene su independencia económica y no necesariamente existe un fondo común. Es decir, si bien parte de los ingresos van destinados a los gastos que comparte la pareja de manera igualitaria - 50/50 - los recursos económicos de las partes no son comunes, sino que admite un mayor grado de individuación. Como expresó una trabajadora no docente de 34 años:

Nos dividimos absolutamente todo. Compramos en el supermercado y nos dividimos a la mitad. Luz, gas, teléfono, todo lo que usamos en conjunto lo dividimos.

E: La gestión de ir a pagar eso, ¿quién lo hace?

Revista Zona Franca- Centro de estudios interdisciplinario sobre las mujeres (CEIM)- Maestría poder y sociedad desde la problemática de género (MG), Rosario, Argentina. ISSN, 2545-6504 http://zonafranca.unr.edu.ar/index.php/ZonaFrancal Número 28 (2020). 
Algunas cosas él, otras yo. Tenemos todo en Pagomiscuentas y eso, así que está resuelto.

E: Ah, re bien. Sos vos (risas). Si vos me tuvieras que decir un poco de la distribución de los gastos que vos me decís que es mitad y mitad, ¿que paga él y qué pagas vos?

Todo es a medias. Todo. Comida, gastos... Hay cosas... lo que sea... Hay veces que compro 10 paquetes de toallitas, pero lo termina pagando igual. No hay un arreglo fijo de esto si o no. La compra general se divide a la mitad y listo. La compra se hace una vez por mes en Makro.

E: Los gastos pagan mitad a mitad, ¿cómo?

Factura a factura.

Este testimonio, si bien muestra un extremo de lo que podríamos llamar una gramática igualitarista, resulta modélico de lo que sucede en buena parte de las personas entrevistadas. Incluso cuando la división 50/50 no es tan extrema, sucede esa búsqueda del equilibrio. Como nos compartía un hombre de 38 años que cumple la doble función docente y no docente: "Uno puede pagar más, uno menos, pero se va equilibrando en el día a día y en el mes a mes, es equilibrio". Incluso otra docente consignaba que con su pareja hacían uso de una planilla de Excel como dispositivo de gestión que le permite ganar precisión a la hora de dividir los gastos.

A diferencia de las parejas que sostienen una bolsa común, las que plantean un acuerdo 50/50 lo hacen a partir de decisiones más discutidas y argumentadas, producto de situaciones puntuales. Hace más probable la posibilidad de mantener intereses propios por fuera de la pareja o familia. Así lo comentó una docente de 56 años:

No, no... esas cosas las vamos hablando, qué se yo. En un momento yo estaba re emputecida con Cablevisión y Fibertel y todo el grupo Magneto, yo decía "saquemos Cablevisión" (...) pero él quería tener cable para ver el fútbol, y yo dije "bueno, te lo pagas vos", "sí, me lo pago yo".

Revista Zona Franca- Centro de estudios interdisciplinario sobre las mujeres (CEIM)- Maestría poder y sociedad desde la problemática de género (MG), Rosario, Argentina. ISSN, 2545-6504 http://zonafranca.unr.edu.ar/index.php/ZonaFrancal Número 28 (2020). 
La decisión de gestionar el dinero en la pareja por medio de la bolsa común o del 50/50 no pareciera estar condicionada necesariamente por la edad, en el caso de este universo entrevistado. Solo en un caso, un trabajador de 42 años señalaba que con su ex pareja tenían discusiones al respecto: "Y también gran parte de las discusiones que tuvimos previos a la separación tiene que ver con el chip de 'Yo soy el macho sostén', 'yo soy el tipo que mantiene la casa' [...]." Sin embargo, el dato generacional no es tan importante como el dato de la comunidad a la que pertenecen. A partir del conjunto de entrevistas podemos advertir que estas personas participan de un universo de sentidos en el que subvertir los modos tradicionales de concebir el dinero en relación con el vínculo afectivo heterosexual está bien visto. Es nuestro convencimiento que esta perspectiva sobre la organización de los vínculos puede explicarse en parte por su participación en el campo académico. Si bien no podemos suponer que exista un solo sentido homogéneo sobre lo que debería ser una pareja, sí nos sorprendió divisar que hay un esfuerzo por identificar sus relaciones como igualitarias, una preocupación que nos animamos a asociar a las clases medias en sus tres sectores (altos, medios y bajos) identificadas con cierto correctismo político de género en el marco de un espacio universitario en el que las políticas de género son muy activas. Por el contrario, sostener figuras tradicionales como la de varón proveedor puede ser desalentador en lo que hace al mantenimiento de vínculos amorosos en este espacio académico. Un docente de 50 años lo expresa muy elocuentemente, incluso para el caso de vínculos entre personas no convivientes:

Si es del mundo académico, a veces pagar yo puede quedar mal. Bueno, si ella quiere pagar ella, si ella quiere pagar mitad y mitad, hago lo que ella quiera, no me meto en esa cuestión.... Si pertenece a otro ámbito, a veces están esperando que pague yo, entonces pago yo.

Según la investigadora Agirre Miguelez (2015), esta gramática se sustenta en modelos de gestión económica que serían condición para equilibrar el poder entre los géneros y alcanzar vínculos más justos, en un contexto cultural en el que

Revista Zona Franca- Centro de estudios interdisciplinario sobre las mujeres (CEIM)- Maestría poder y sociedad desde la problemática de género (MG), Rosario, Argentina. ISSN, 2545-6504 http://zonafranca.unr.edu.ar/index.php/ZonaFrancal Número 28 (2020). 
ya hace décadas que las nociones tradicionales en torno a la proveeduría masculina de los ingresos de la familia estarían, por lo menos discursivamente, en crisis.

\subsection{Donde hay un hombre incapaz nace una mujer gestora}

Al momento de describir la gestión del dinero en la pareja, la mayoría de las personas entrevistadas utilizaron metáforas para explicar quién se ocupa de la administración. En las respuestas pudimos encontrar dos figuras recurrentes que decidimos denominar la mujer gestora y el hombre incapaz. Ciertamente estas figuras irían en contra de la corrección política igualitaria y no-sexista que creemos las personas se ocuparon de transmitir. Nuestro análisis buscará centrarse en los acuerdos realmente existentes para ir más allá de las primeras clasificaciones igualitarias y equitativas que las personas hicieron de sus vínculos.

La figura de la mujer gestora se sustenta principalmente en la imagen de que las mujeres son mejores organizando y gestionando los gastos. Las personas entrevistadas que hacen uso de esta figura no especifican exactamente qué es lo que hacen las mujeres para ser mejores administradoras, pero aseguran que en dicha tarea son superiores a los hombres.

"La plata es de los dos, pero la maneja mi mamá por un tema que ella sabe manejar mejor, administrar. Mi viejo es medio desastre, entonces: 'bueno, ocupate vos'” dijo una estudiante de 23 años sobre la gestión del dinero en su casa. De la misma manera, un trabajador no docente de 33 años manifestó que, en la pareja, es la mujer quien se ocupa de los gastos: “(...) Ella es muy obsesiva con pagar todo siempre, y tener todo controlado el tema de los gastos. Sé que si lo hago yo, ella va estar controlando de nuevo. Así que directamente... no, no me molesta".

Será necesario aportar al análisis que la concepción de las mujeres como buenas administradoras es una característica socialmente atribuida, pues responde al imaginario de que la mujer será quien mejor resguarde los intereses

Revista Zona Franca- Centro de estudios interdisciplinario sobre las mujeres (CEIM)- Maestría poder y sociedad desde la problemática de género (MG), Rosario, Argentina. ISSN, 2545-6504 http://zonafranca.unr.edu.ar/index.php/ZonaFranca| Número 28 (2020). 
de la familia. Esto es, se ocupará de la educación, la alimentación y los cuidados en general de quienes conforman esa unidad. No es únicamente un criterio micro ni exclusivo de este conjunto de individuos, sino que es consecuente con ideales macro que reproduce también el Estado argentino. En 2009 se estableció que para la Asignación Universal por Hijo sería la madre quien tendría prioridad sobre el padre en la titularidad de la prestación. El criterio según el cual las mujeres gestionan y administran mejor el dinero acompaña el diseño de las políticas públicas a nivel internacional. Este tipo de discursos que sostienen luego la materialidad de la administración atribuida a las mujeres, fue ampliamente explorado por Martín Hornes (2016) que estudió cómo las ideas sobre la maternidad y los cuidados permeaban los discursos sobre la percepción de la $\mathrm{AUH}$. Las mujeres son mejores destinatarias porque son quienes destinarían esos ingresos a sus hijos y/o hijas.

Así como es una característica externamente atribuida, también es personalmente asumida por las mismas mujeres. Una docente nos comentaba que los varones de su casa carecían de habilidades para el control de sus gastos y agregaba: "Siempre me pareció que la mujer era mejor administradora". Son frecuentes también los casos en los que los varones dejan en manos de sus parejas mujeres la administración de sus sueldos para el pago de los gastos de la unidad familiar.

Por su parte, la figura del hombre incapaz está estrechamente relacionada con la mujer gestora. Los espacios que un hombre incapaz no puede ocupar son las tareas que (nuevamente) recaen sobre las mujeres. En las entrevistas se manifiesta que no son los hombres quienes administran el dinero en la pareja por una cierta incapacidad que se entrelaza con la supuesta virtud administrativa innata de las mujeres. Una docente de 56 años manifestó esta característica propia de las mujeres: "cuando administran ellos [el hijo y el marido] nunca llegamos (risas) porque por ahí lo distribuye mal, lo distribuye tan mal que entonces... es el criterio, entonces siempre me pareció que la mujer era mejor

Revista Zona Franca- Centro de estudios interdisciplinario sobre las mujeres (CEIM)- Maestría poder y sociedad desde la problemática de género (MG), Rosario, Argentina. ISSN, 2545-6504 http://zonafranca.unr.edu.ar/index.php/ZonaFrancal Número 28 (2020). 
administradora". Por su parte, otra trabajadora no docente de 35 años contó que su novio es volado y no puede ocuparse de la gestión del dinero: "Yo medio que manejo todas las cuentas de la casa, pero por una cuestión de estructura que yo tengo en la cabeza, y de prolijidad. Él por ahí es más volado con esas cosas...".

Contraria a la hipótesis de la psicoanalista Clara Coria (2008) -quien trabajó sobre el concepto de sexuación del dinero y en muchas de sus referencias se encuentra alineada con la visión simmeliana del dinero-, aquí no existe una identificación del mismo con los varones. No son ellos quienes están en una relación naturalizada con el dinero, sino que algunos de estos sentidos se han empezado a resquebrajar. Esto hace que convivan, por un lado, sentidos tradicionales asociados a lo femenino como buena administradora. La buena administradora no es más ni menos que la extensión de la idea de buena cuidadora. Pero, por otro lado, también admite el desprendimiento de la dependencia económica, abriendo un espacio para el agenciamiento de la administración de la economía de la pareja. Aun así, en las entrevistas se deja entrever que, junto a un horizonte igualitarista, convive un imaginario sobre la conexión entre feminidad y administración de los gastos del hogar que convalida la hipótesis de la extracción de trabajo amoroso de las mujeres.

Ambas figuras aparecieron en las respuestas de las personas entrevistadas como justificaciones de acuerdos implícitos de cada pareja, ninguna persona expresó haber conversado con su pareja sobre quién sería aquella encargada de gestionar el dinero. En este sentido, las figuras de mujer gestora y hombre incapaz funcionan como metáforas que les permiten a las personas ordenar el dinero y el afecto sin conversar explícitamente sobre ello. Particularmente las parejas que participan del mundo académico evidencian esfuerzos llamativos por sostener una gramática de la equidad en las relaciones de género que convive con imaginarios tradicionales y prácticas materiales efectivas de administración del gasto del hogar que se condice con una extracción del trabajo amoroso.

Revista Zona Franca- Centro de estudios interdisciplinario sobre las mujeres (CEIM)- Maestría poder y sociedad desde la problemática de género (MG), Rosario, Argentina. ISSN, 2545-6504 http://zonafranca.unr.edu.ar/index.php/ZonaFranca| Número 28 (2020).

Página 223 
Habiendo atravesado el análisis, consideramos que si bien este conjunto de individuos cree que los acuerdos monetarios en sus parejas son igualitarios, la gestión y la responsabilidad sobre los gastos recaen frecuentemente en manos de la mujer gestora. Tanto la figura de bolsa común como la de 50/50 reflejan que el ingreso de las mujeres sería considerado de igual valor simbólico que el ingreso de los hombres, aun cuando el monto percibido por cada miembro sea distinto. Allí se renuevan los sentidos asociados a la equidad. Sin embargo, ambos modelos de gestión del dinero reproducen la figura de la mujer como encargada de la administración y del cuidado de los ingresos. La caracterización que sostiene a la mujer gestora no sólo es atribuida por el entorno sino también, asumida por las propias mujeres. De esta manera, cabe preguntarnos si el elogio hacia su capacidad administrativa estaría funcionando como un velo para perpetuar la feminización de las tareas del hogar.

\section{Los cuidados y la fractura de la equidad}

Previamente indagamos sobre las figuras del hombre incapaz y de la mujer gestora. También analizamos cómo esta última responde a un supuesto que marida la feminidad con una eficiente, correcta y responsable manera de administrar el dinero y los gastos dentro del grupo familiar. Al abordar la cuestión de los cuidados, encontramos en el discurso de las personas entrevistadas la continuidad de estas figuras e identificamos una fractura en el ideal de equidad. Cuando pensamos la noción de cuidado lo hacemos desde una perspectiva de la economía del cuidado. Entendemos las tareas de cuidado como todas aquellas destinadas a satisfacer las necesidades básicas de existencia de las personas: el cuidado directo, el autocuidado, las tareas domésticas y la gestión del cuidado (Rodríguez Enríquez, 2017).

\section{1. Él a veces barre y ella es una obsesiva}

Revista Zona Franca- Centro de estudios interdisciplinario sobre las mujeres (CEIM)- Maestría poder y sociedad desde la problemática de género (MG), Rosario, Argentina. ISSN, 2545-6504 http://zonafranca.unr.edu.ar/index.php/ZonaFranca| Número 28 (2020). 
Las valoraciones que las personas entrevistadas hacen sobre sus modos de distribuir las tareas de cuidado con sus parejas nos muestran que no hay un intento por sostener el discurso sobre la equidad en este terreno. Una estudiante de 31 años decía lo siguiente con respecto a la distribución de las tareas: "Muy desigual. Él se ocupa de pocas cosas, lava los platos, cuelga la ropa y a veces barre. No hay ninguna tarea para él. Limpiar un inodoro, tender la cama no, no". Del mismo modo un docente de 39 años expresó: "En general compartimos bastante, pero bueno, no es cincuenta y cincuenta. Siempre hay un sesgo a favor mío digamos".

Al abordar estas cuestiones en las entrevistas, la justificación sobre la distribución de las tareas de cuidado distancia a los hombres de estas actividades, en gran parte de los casos no participan de ellas. Además, algunos se sienten en un estado de aprendizaje. Un hombre no docente de 31 años expresó lo siguiente:

Yo soy medio un desastre, la verdad es que, si no me dice "che, dame una mano con eso o aquello", yo la verdad cocino siempre, pero hay cosas que no, no las veo. Realmente, no me hago el gil, no las veo porque no me doy cuenta, no las tengo incorporadas.

Por otro lado, una docente de 31 años dijo "[...] olvidate de que te barra o que te limpie, eso no y es verdad que ni se da cuenta, me parece", haciendo referencia a su pareja. En ocasiones y en menor medida encontramos que las personas entrevistadas se remitieron a los patrones de socialización primaria para explicar el porqué de las divisiones desiguales. Esto lo podemos ver en el testimonio de un hombre no docente de 33 años que contó lo siguiente: "Yo me crié en una casa donde éramos 6 hermanos. $Y$ era un quilombo todo el tiempo. [...] Me cuesta horrores, no porque no quiera hacer, sino porque no tengo la costumbre de hacerlo" cuando fue consultado sobre el modo en que reparten las tareas. Por otro lado, una mujer no docente de 35 años nos dijo:

Revista Zona Franca- Centro de estudios interdisciplinario sobre las mujeres (CEIM)- Maestría poder y sociedad desde la problemática de género (MG), Rosario, Argentina. ISSN, 2545-6504 http://zonafranca.unr.edu.ar/index.php/ZonaFranca| Número 28 (2020). 
Él es un pibe también que viene de criarse un poco solo, de hacerse sus propias cosas, nunca dependió demasiado de nadie [...] yo por ahí soy más estructurada, más ordenada, más prolija con los trámites, con las cuentas, con... si hay que pedir un turno médico, o sea, esas cosas que medio que lo llevo yo a que sea un poco más ordenado en ese sentido.

Si bien en muchos casos las personas entrevistadas se esforzaron por demostrar conciencia sobre un cambio de paradigma, al menos en lo discursivo, cuando se abordan cuestiones estrechamente ligadas a la relación de la mujer con las tareas de cuidado, no parece existir una ruptura concreta con los patrones socialmente aprendidos e incorporados. Por el contrario, lo que aparece es un intento por dejar asentado su conocimiento de ello.

Por otro lado, vemos que se trata de discursos que funcionan en espejo con una concepción de las mujeres en relación a la eficacia en la ejecución de las tareas. En este sentido, son recurrentes las afirmaciones que hacen las mujeres de sí mismas como perfeccionistas del orden, de la limpieza y en general de todas las tareas de cuidado. Por ejemplo, una mujer no docente de 35 años explicó enfáticamente:

[...] Con el orden y todo eso, él es un despelotado y me dice "No, dejá que mañana lo ordeno", pero a mí como me gusta que esté ordenado voy y lo hago yo. Pero ahí creo que a veces la culpa la tenemos las mujeres porque en realidad yo lo hago porque pienso que él lo hace mal.

A su vez un docente de 40 años contaba lo siguiente: "Las tareas del hogar las tratamos de dividir todo lo que podamos, yo soy muy... quizás mi compañera es muy obsesiva con ciertas cosas y, quizás, yo no."

Estas narrativas son manifestadas tanto por mujeres como por hombres y mantienen una línea. Podemos enmarcarlas dentro de lo que conocemos como la naturalización de la capacidad de las mujeres para cuidar como uno de los factores explicativos de la distribución desigual entre varones y mujeres de las responsabilidades de cuidado. Tal y como sostiene Corina Rodríguez Enríquez

Revista Zona Franca- Centro de estudios interdisciplinario sobre las mujeres (CEIM)- Maestría poder y sociedad desde la problemática de género (MG), Rosario, Argentina. ISSN, 2545-6504 http://zonafranca.unr.edu.ar/index.php/ZonaFrancal Número 28 (2020). 
(2017), esta naturalización se apoya sobre argumentos biológicos que ubican a la mujer cis como aquella con capacidades superiores al hombre para llevar adelante aspectos referidos al cuidado. Lejos de ser una capacidad natural, se trata de una construcción cultural sostenida por distintas instituciones que lleva a las mismas mujeres a imponerse estos mandatos y sentir culpa al no responder a ellos. Estas fueron ideas profundamente estudiadas por Silvia Federici (2018) para quien el trabajo doméstico es el trabajo que fue transformado en un atributo natural inherente al aspecto más profundo del carácter y la psique de las mujeres. Es interesante destacar que en el relato de las personas entrevistadas, incluso del ámbito académico en donde el sentido común insinuaría una cierta crítica a aquellas lógicas que reproducen las desigualdades, dichas concepciones son afirmadas y asimiladas dentro de sus vínculos.

Al mismo tiempo, pero en menor medida, identificamos una desvalorización por las responsabilidades de cuidado. Tal es el caso de un no docente de 40 años que al hacer referencia a su ex pareja, quien se encontraba a cargo de las tareas de cuidado, expresó lo siguiente: "[...] yo siempre respeté el lugar que ella tuvo como mi compañera más allá de que no aportaba en el sostén del hogar."

En este sentido, los relatos que enfatizan una división entre trabajos "productivos", es decir aquellos que son asalariados y los trabajos "no productivos", aquellos que no son asalariados, pueden ser problematizados tomando como eje la obra de Federici. La autora sostiene que para comprender la supremacía masculina y las lógicas sobre el funcionamiento del sistema capitalista es fundamental tener presente el sistemático confinamiento de la mujer en el desarrollo de tareas históricamente desvalorizadas, aunque constituyen la base sobre la cual se reproduce la vida (Federici, 2018)

Por último, dentro de las tareas de cuidado, podemos identificar una distinción entre aquellas vinculadas específicamente al cuidado de niños y niñas con respecto a las demás tareas. Cuando los entrevistados hombres hacen

Revista Zona Franca- Centro de estudios interdisciplinario sobre las mujeres (CEIM)- Maestría poder y sociedad desde la problemática de género (MG), Rosario, Argentina. ISSN, 2545-6504 http://zonafranca.unr.edu.ar/index.php/ZonaFranca| Número 28 (2020). 
referencia al cuidado de menores, encontramos en algunos casos, dentro del claustro docente, la idea de la responsabilidad compartida. Uno de ellos nos decía lo siguiente cuando fue consultado sobre la forma en la que reparte con su pareja el cuidado de su hijo: "La patria potestad es compartida en Argentina así que tenemos la misma responsabilidad, la misma carga. No doy la teta, pero es lo único." En estos casos, los hombres se muestran más cercanos a participar en estas tareas y la idea de la distribución equitativa está más presente.

\subsection{La carga mental}

La reproducción de estas prácticas nos lleva a hablar de otro aspecto fundamental. La carga mental aparece en el relato de algunas entrevistadas mujeres como un fantasma. Es una dimensión latente de las tareas de cuidado que podemos pensar como parte de las mismas incluso en momentos en las cuales estas no estarían siendo llevadas a cabo. Una entrevistada afirmó estar asistiendo a terapia cuando fue consultada sobre las tareas de mantenimiento del hogar. También, una docente de 35 años, al ser consultada sobre el modo en que ella concebía la distribución de las tareas del hogar, expresó lo siguiente:

Una cosa que noto es que la casa puede estar detonada y él se sienta a ver tele si puede. La casa está detonada y yo no me puedo sentar a ver tele. Entonces es como la carga mental que yo veo que no tiene él. Pero bueno, no estoy diciendo nada nuevo [...]

Por otro lado, una docente de 43 años, cuando se refirió al cuidado de sus hijas nos dijo: "[...] todo ese cronograma está en mi mente y en la suya no, entonces, lógico, me saca energía a mí y a él no, la única energía de él es llevarlas y buscarlas".

Atendiendo a estos discursos podemos remitirnos a Jonasdottir (2011) quien, desde una perspectiva marxista, entiende al amor humano como una capacidad posible de ser explotada de modo tal que incluso en contextos de aparente

Revista Zona Franca- Centro de estudios interdisciplinario sobre las mujeres (CEIM)- Maestría poder y sociedad desde la problemática de género (MG), Rosario, Argentina. ISSN, 2545-6504 http://zonafranca.unr.edu.ar/index.php/ZonaFranca| Número 28 (2020). 
equidad de las condiciones socio-económicas en relaciones sexo-afectivas heterosexuales se da una explotación de la capacidad de amar de la mujer. Podemos traer estas discusiones a un terreno latinoamericano cuando pensamos los vínculos de las personas entrevistadas, teniendo en cuenta que pertenecen a una clase media en donde, en general, existe una aparente igualdad socioeconómica.

En línea con la figura de la mujer gestora y el hombre incapaz, vemos que, si bien algunas de las personas entrevistadas hacen referencia a una búsqueda de equilibrio, predominan las afirmaciones sobre una desigual distribución de las tareas. Las justificaciones sobre esta distribución, en algunos casos, muestran una estrecha relación con la carga mental En ocasiones, algunas entrevistadas manifestaron estar pendientes del modo en que sus parejas o los integrantes de sus familias se hacen cargo de las tareas del hogar. Tal es el caso de una docente de 56 años que dijo: "Más o menos cada uno colaboramos un poco. [...] [...] Yo por ejemplo hace poco sí, puse yo unos carteles al lado de los interruptores de luz que dicen: ‘ ¿limpiaste? ¿Lavaste? ¿Barriste?’”. También podemos mencionar el relato de otra docente de 56 años que expresaba: "Soy la referente del cuidado en general que tiene que ver con marcar esto: 'Che, te corresponde esto', '¿te tomaste la pastilla?', no sé." Haciendo énfasis en estas declaraciones y retomando la idea de la disociación del hombre con las tareas de cuidado, observamos que no hay una división explícita de las tareas y el rol que cada integrante de la familia debe ocupar, sino más bien, lugares vacíos para que la buena gestora, la buena cuidadora y la obsesiva explote nuevamente sus capacidades.

Cuando pensamos en el aspecto generacional, si nos concentramos en personas que no superan los 30 años, también encontramos narrativas ligadas a la desigualdad en cuanto a las tareas de cuidado. Es el caso de una estudiante de 25 años quien al hablar sobre el cuidado de su hija que expresó:

Revista Zona Franca- Centro de estudios interdisciplinario sobre las mujeres (CEIM)- Maestría poder y sociedad desde la problemática de género (MG), Rosario, Argentina. ISSN, 2545-6504 http://zonafranca.unr.edu.ar/index.php/ZonaFranca| Número 28 (2020). 
E: Cuando hablabas de las responsabilidades que tenía que tener un padre, ¿A qué te referías?

El padre [...] estuvo presente los dos primeros años como un padre de juego, un padre didáctico, nunca realmente se ocupó de las actividades que conlleva tener un pibe. Yo lo acepté [...] Para mí ser padre es ir al colegio, educarla, no sé, viste. Hay un montón de cosas que le enseño (ella a su hija), a formarse como persona y que ella aprenda sus caminos con lo chiquita que es y acepte las realidades que le tocan vivir con el padre que tiene. Digo, esas cuestiones que hacen, digo la construcción del lazo materno que yo construí con ella me hacen ser madre a mí.

E: ¿Qué son esas actividades que debería hacer que lo hacen ser padre? Yo creo que estar presente en el día a día, y más que nada preocuparse, digo, construir lazos con tu hija, enseñarle cosas, no sé...educarla. Pero educarla en el sentido de, como persona, como de ser social, no en el sentido educación de colegio. En sí el hecho de estar y preocuparse, para mí, es lo que te hace ser un padre. $Y$ bueno, y cumplir con tus responsabilidades, si, bueno el dinero y esas giladas también. Pero yo voy más desde lo afectivo.

Este relato no solo nos muestra explícitamente una idea que desvincula la paternidad ligada únicamente a un sustento económico, sino que, pone en juego y nos hace pensar en la relación que guardan las tareas de cuidado con lo afectivo como factor que involucra a las partes de un grupo familiar, en un espacio que, como comentamos previamente, es ocupado por una mujer que explota sus capacidades de amar. Tal vez haya lugar para pensar en una ruptura con estas lógicas si atendemos a otros testimonios como el de una estudiante de 23 años quien nos comentó una discusión con su madre sobre las tareas que le son asignadas en relación a las que le corresponde a su hermano:

Yo agarré una vez y le planteé, le digo “¿Qué se espera acá, que yo soy la que lo tiene que limpiar? Porque vivimos tres. Está bien, vos trabajas, estás cansada. De los que no trabajamos - mi hermano y yo-, ¿por qué cae sobre mí? ¿porque soy mujer?” Está mal para mí. Y si es porque soy

Revista Zona Franca- Centro de estudios interdisciplinario sobre las mujeres (CEIM)- Maestría poder y sociedad desde la problemática de género (MG), Rosario, Argentina. ISSN, 2545-6504 http://zonafranca.unr.edu.ar/index.php/ZonaFrancal Número 28 (2020). 
la hermana mayor, también está mal porque, o sea, no digo que no tengo que limpiar —de hecho, lo hago—, pero me parece que no debería ser la única.

Si bien los reclamos que nos cuenta esta entrevistada corresponden a una estudiante que convive con su madre y no se encuentra a cargo de una familia podríamos pensarlo como un intento de subversión de los patrones adquiridos. Si vemos en conjunto las entrevistas, es frecuente que los individuos sostengan una narrativa de la igualdad y el equilibrio como un ideal a conseguir en la pareja. Sin embargo, las distribuciones no son equitativas y podríamos pensar que incluso desde ámbitos académicos donde, como hemos visto, a veces se impugnan modos de acción y percepción patriarcales heredados y se reclama la igualdad de oportunidades, la discusión debe calar más hondo para poder comprender qué desigualdades se están perpetuando en los vínculos sexo-afectivos.

\section{Reflexiones finales}

Este trabajo tuvo como objetivo analizar cómo se fusionan tensionándose el discurso sobre la equidad en los vínculos sexo-afectivos y sus prácticas respecto de la gestión del dinero y los cuidados. En este sentido, buscamos indagar qué había detrás de las supuestas divisiones igualitarias en la gestión del dinero y la realización de las tareas del hogar. En función de esto, decidimos trabajar sobre las metáforas y figuras a las que las personas recurrían para hablar sobre esta temática.

En relación con la gestión del dinero, los sujetos entrevistados se ocuparon imperiosamente de transmitir una imagen de igualdad en sus vínculos sexoafectivos. Esta pretensión de igualdad fue manifestada, principalmente, a través de lo que identificamos como las figuras de bolsa común y 50/50. Dichas metáforas nos permitieron comprender que los vínculos heterosexuales analizados le otorgan una importancia a la división equitativa de los gastos monetarios que atañen a la pareja.

Revista Zona Franca- Centro de estudios interdisciplinario sobre las mujeres (CEIM)- Maestría poder y sociedad desde la problemática de género (MG), Rosario, Argentina. ISSN, 2545-6504 http://zonafranca.unr.edu.ar/index.php/ZonaFranca| Número 28 (2020). 
A lo largo del análisis, pudimos identificar que lo que aparece como pretensión de equidad dentro de las parejas, es una característica que se relaciona estrechamente con la población entrevistada: trabajadores y estudiantes de la universidad. Las personas que trabajan y estudian allí se sienten cómodas cuestionando las prácticas patriarcales heredadas y proponiendo nuevos mecanismos de gestión y división del dinero en sus vínculos sexo-afectivos. Entendemos que la universidad, como espacio privilegiado de las clases medias (aún medias-bajas, como se indica en la composición del estudiantado) sostiene al pensamiento crítico como un valor. En este caso la crítica es referida a las relaciones afectivas, dado que en esa universidad en particular las políticas de género han tenido una presencia significativa en asumir los conflictos en torno a la violencia de género y la formación y capacitación de los claustros. Esto nos permite pensar que existe, en este espacio singular, un vínculo entre sectores medios y cierta crítica a tradicionalismos que funciona como una especie de sentido común ligado a sectores progresistas que, a su vez, tiene por efecto la expresión de sus relaciones sexo-afectivas bajo un horizonte igualitarista.

Sin embargo, al indagar sobre los modos en que se gestiona el dinero (tanto si se cumple una división 50/50 o una bolsa común), aparecen recurrentemente otras dos figuras que elegimos denominar la mujer gestora y el hombre incapaz. A partir de tales figuras, pudimos identificar las primeras grietas en la pretendida igualdad, ya que dichas metáforas les permitían a las personas entrevistadas continuar cargando a las mujeres con tareas de responsabilidad administrativa. Las mujeres aparecían como las únicas capaces de llevar adelante una buena administración del dinero del hogar o de la pareja.

Al continuar el análisis, hallamos que los sentidos igualitaristas que circulan encuentran un límite en la división de las tareas del hogar y de cuidados de otras personas a cargo, en los casos en que correspondía. Al ser interrogados/as sobre el reparto de estas tareas, el discurso no aparecía ya con pretensiones equitativas, sino que se vislumbraban con más facilidad las desigualdades que continúan

Revista Zona Franca- Centro de estudios interdisciplinario sobre las mujeres (CEIM)- Maestría poder y sociedad desde la problemática de género (MG), Rosario, Argentina. ISSN, 2545-6504 http://zonafranca.unr.edu.ar/index.php/ZonaFranca| Número 28 (2020). 
recargando a las feminidades con dichas tareas. Es decir, que en relación con las tareas de cuidado el ideal igualitario deja de sostenerse, incluso desde el discurso. A su vez, en los casos que sí mantienen un discurso sobre la equidad, las mujeres soportan una carga mental en relación a la responsabilidad sobre las tareas del hogar que los hombres no poseen.

A pesar de haber entrevistado personas de distintos rangos etarios, encontramos que los discursos no tenían grandes diferencias entre personas mayores y jóvenes. La pretensión de igualdad y las grietas que mostraron desigualdades atravesaron la mayoría de las entrevistas. A su vez, tanto hombres como mujeres sostenían las figuras mencionadas anteriormente y las mujeres entrevistadas, en su mayoría, reproducen las metáforas que las sobrecargan con las tareas de cuidado y de gestión del dinero.

Considerando los hallazgos aquí expuestos, consideramos importante poder abrir nuevas preguntas sobre el vínculo entre, por un lado, los sectores medios que participan del campo universitario y su permeabilidad a cuestionar sentidos instituidos acerca de las relaciones afectivas $y$, por otro, sus esfuerzos por sostener y recrear cierta ficción igualitarista que parece ocultar desigualdades en el orden de la materialidad al interior de estos vínculos.

\section{Bibliografía}

AGIRRE MIGUÉLEZ, Amaia (2015). "El dinero en la pareja: reflexiones sobre relaciones de pareja igualitarias". En RES Revista Española de Sociología, No 23, pp. 9-27. Recuperado de https://recyt.fecyt.es/index.php/res/issue/view/3320

BENERÍA, Lourdes y ROLDÁN, Martha (1987). Las encrucijadas de clase y género. Trabajo femenino, subcontratación y dinámica de la unidad doméstica en la Ciudad de México. Fondo de Cultura Económica; El Colegio de México, México.

BLANCO, Rafael (2014). Universidades íntimas y sexualidades públicas. La gestión de la identidad en la experiencia estudiantil. Miño y Dávila, Buenos Aires.

Revista Zona Franca- Centro de estudios interdisciplinario sobre las mujeres (CEIM)- Maestría poder y sociedad desde la problemática de género (MG), Rosario, Argentina. ISSN, 2545-6504 http://zonafranca.unr.edu.ar/index.php/ZonaFranca| Número 28 (2020). 
BOURDIEU, Pierre. y PASSERON, Jean Claude (2009) Los herederos: los estudiantes y la cultura. Siglo XXI, Buenos Aires.

CORIA, Clara (2007). "La sexuación del dinero. Conflictos Subjetivos en la 'masculinidad', en la "feminidad" y su repercusión en la vida cotidiana de mujeres y varones". En Congreso Internacional SARE "Masculinidad y vida cotidiana", EMAKUNDE/ INSTITUTO VASCO DE LA MUJER, pp. 265-280. Recuperado de https://www.euskadi.eus/contenidos/informacion/gizonduz areas documentos/es def/adjuntos/coria.c 07 cast.pdf

CANEVARO, Santiago (2008). "Al final de la jornada, todo cambia, todo queda. Economía pública y economía doméstica en el siglo XXI". En Apuntes del CECYP (14), p. 203-209. Recuperado de http://www.apuntescecyp.com.ar/index.php/apuntes/article/view/298/266

FEDERICI, Silvia (2018). Revolución en punto cero: trabajo doméstico, reproducción y luchas feministas. Tinta Limón, Buenos Aires.

HOCHSCHILD, Arlie (2011). La mercantilización de la vida íntima. Apuntes de la casa y el trabajo. Katz Editores, Buenos Aires.

HORNES, Martín (2016). "Entre condiciones expertas y negociaciones prácticas. La generización del dinero proveniente de las transferencias monetarias condicionadas." Horizontes Antropológicos, $\mathrm{N}^{\circ}$ 45, pp. 77-104. Disponible en https://www.scielo.br/pdf/ha/v22n45/0104-7183-ha-22-45-0077.pdf

IBÁÑEZ PASCUAL, Marta (2008). “La «bolsa común» en las parejas: algunos significados y algunas trampas." Papers Revista de Sociología, № 87, pp. 161185. Disponible en https://dialnet.unirioja.es/servlet/articulo?codigo $=2598607$

ILLOUZ, Eva (2012). ¿Por qué duele el amor? Una explicación sociológica. Katz, Buenos Aires.

JÓNASDÓTTIR, Anna (1993). El poder del amor. ¿Le importa el sexo a la democracia? Cátedra, Col. Feminismos, Madrid.

JÓNASDÓTTIR, Anna (2011). “¿Qué clase de poder es ‘el poder del amor’?” Revista Sociológica, $N^{\circ}$ 74, pp. 247-273. Disponible en 


\section{http://www.scielo.org.mx/pdf/soc/v26n74/v26n74a8.pdf}

MARENTES, Maximiliano (2020). "Dinero amoroso. Sentidos sociales del dinero en parejas gais argentinas." RELIES: Revista del Laboratorio Iberoamericano para el Estudio Sociohistórico de las Sexualidades, N², pp. 2657. Disponible en https://www.upo.es/revistas/index.php/relies/article/view/4610

PALUMBO, Mariana (2018). Pensar(nos) desde adentro. Representaciones sociales y experiencias de violencia de género. UNSAM Edita, San Martín.

PUGLIA, María de las Nieves (2016). "Lejos de la venta del cuerpo: gestiones corporales y simbólicas en trabajadoras sexuales." Revista Astrolabio, NN16, pp. 5-32. $\quad$ Disponible en https://revistas.unc.edu.ar/index.php/astrolabio/article/view/14226/14706

PUGLIA, María de las Nieves (2017) "'Quería que le limpiaran todo, la casa y el sable': del servicio doméstico a la construcción subjetiva de la prostitución como oficio en Argentina." Revista Interdisciplinaria de Estudios de Género del Colegio de México. Vol. 3, $\quad \mathrm{N}^{\circ} 6$, pp. 127-158. Disponible en http://estudiosdegenero.colmex.mx/index.php/eg/article/view/156

RODRÍGUEZ ENRÍQUEZ, Corina (2018). "Economía del cuidado y desigualdad en América Latina: Avances recientes y desafíos pendientes". En Carrasco Bengoa, C. y Díaz Corral, C. (Eds.) Economía Feminista: desafíos, propuestas, alianzas. pp. 133-156. Madreselva, Buenos Aires.

ROVETTO, Florencia y FIGUEROA, Noelia (2017). "Que la universidad se pinte de feminismos para enfrentar las violencias sexistas." Descentrada, Vol. 1, $\mathrm{N}^{\circ} \quad 2, \quad$ pp. $\quad 1-6 . \quad$ Disponible en

\section{https://www.descentrada.fahce.unlp.edu.ar/article/view/7744}

SVAMPA, Maristella (2005). La sociedad excluyente. Argentina bajo el signo del neoliberalismo. Taurus, Buenos Aires.

VAZQUEZ LABA, Vanesa y PALUMBO, Mariana (2019). Causas y efectos de la discriminación y la violencia de género en el ámbito universitario. Descentrada,

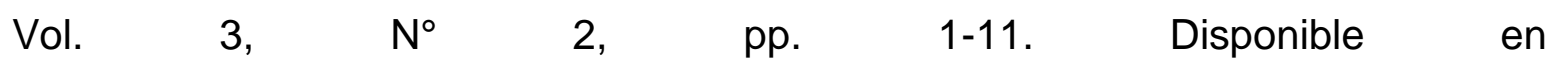

Revista Zona Franca- Centro de estudios interdisciplinario sobre las mujeres (CEIM)- Maestría poder y sociedad desde la problemática de género (MG), Rosario, Argentina. ISSN, 2545-6504 http://zonafranca.unr.edu.ar/index.php/ZonaFrancal Número 28 (2020). 
"Ella es una obsesiva y él está aprendiendo": imaginarios y desigualdad material en las relaciones sexo-afectivas de miembros de la comunidad universitaria

https://www.descentrada.fahce.unlp.edu.ar/article/download/DESe093/11161?inlin

$\underline{\mathrm{e}=1}$

WILKIS, Ariel (2013). Las sospechas del dinero. Paidós, Buenos Aires.

ZELIZER, Viviana (2006). "Money, power and sex." Yale Journal of Law and

Feminism, Vol. 18, $\mathrm{N}^{\circ}$ 1, pp. 303-315. Disponible en

https://papers.ssrn.com/sol3/papers.cfm?abstract id=944055

ZELIZER, Viviana (2009). La negociación de la intimidad. Fondo de Cultura

Económica, Buenos Aires.

Revista Zona Franca- Centro de estudios interdisciplinario sobre las mujeres (CEIM)- Maestría poder y sociedad desde la problemática de género (MG), Rosario, Argentina. ISSN, 2545-6504 http://zonafranca.unr.edu.ar/index.php/ZonaFranca| Número 28 (2020). 